\title{
Theory and Problems of Translation Studies
}

\author{
Dr. N. B. Shama Bharathi \\ Lecturer in English, SVGM Government Degree College, Kalyandurg-515761,Ananatpur-District,Andhra \\ Pradesh-India
}

\begin{abstract}
It is an introductory, and it will present a brief background to the importance of trans-cultural communication. It also presents the types and problems of translation, objectives, the scope and the methodology underlying the present study
\end{abstract}

Key words: Interaction, translation, communication, cultural and linguistic heritage

\section{Introduction}

Mankind all over the world speak and communicate their feelings in different and numerous languages and dialects, which differ from community to community and from region to region. Interaction and mutual understanding cannot take place among different communities speaking thousands of different, mutually unintelligible languages throughout the world; this creates problems of communication and hence the need arises for communication among different linguistic communities of the world through an alternative means for conveying information from one language to another. Translation can fill this gap effectively and promote interstate, international-and trans-cultural communication. Historically languages have been transmitted from one generation-to another by habit formation and not by heredity.

Even though the term 'translation' cannot be defined precisely, scholars and theorists have attempted to describe it. Some of these definitions are presented below.

Dr. Samuel Johnson defined translation as involving the process of "change into another language, retaining the sense" which is indeed a basic objective. ${ }^{1}$

Modifying this statement A.H. Smith maintains: "To translate is to change into another language retaining as much of the sense as one can.",2

J.C. Catford defines translation from a linguistic point of view: Translation may be defined as "the replacement of textual material in one language (SL) by equivalent textual material in another language (TL).,"3

The performance of translation work is an endeavor to mediate between different cultures, languages, texts and nationalities. Hence "translation as an activity means moving from one language to another -which again means the replacement of textual material in one language by appropriate textual material from another language." 4

Translation has become an utmost necessity for the educational, social, economic, scientific, technological and political developments at the global level for maintaining international and mutual amity. Each community has its own language and each language has its speech community and its own cultural and linguistic heritage. So translation is a means for initiating and promoting cross-cultural communication. In this way translation can play a crucial role in bringing closer divergent socio-cultural groups by enabling mutual appreciation of their cultures and information. Thus a translator renders a noble service to mankind by providing access to texts, of eternal value, such as the Vedas, The Upanishads, The Meemamsas and Darshana

Sastras, The Geetha, The Bible, The Koran and all other literatures of wisdom, knowledge and science; and all these works have been made accessible to humanity solely through their translation into different languages of the world. The credit for this dissemination goes to the translators and their sponsors. Its importance in general and with reference to India in particular is mentioned as follows:

(1) In the words of K.M. George "Modern transport and communication technology have advanced so much in recent years that the globe has shrunk into a village. Hills and valleys, waters and forests have lost their significance as barriers owing to the advanced means of transport. But languages are still barriers in communication and the solution is still translations". Hence the need for translation is imminent. ${ }^{5}$

(2) India has 18 officially recognized languages since 1992. India is believed to have 1652 mother tongues, of which thirty three are spoken by people numbering over a lakh. The Indian languages now in use have evolved from different languages families corresponding more or less to the different ethnic elements that have come into India from the dawn of history. To keep all these diverse language communities in mutual harmony and ensure a smooth transaction of affairs on socio-economic sociopolitical, cultural and scientific fronts throughout the nation, communication among these groups including interaction and exchange of knowledge, information and opinion are all imperative. 
Translation is one of the tools that can effectively contribute to this goal. Translation in India is a socio - cultural necessity for political and ideological integration ${ }^{1}$.

(3) The English language has been recognized as an Associate Official Language by the Constitution of India in view of its role in mass communication and its function as a medium of instruction for higher education and research. It has also been the language of Science and Technology, international diplomatic relations, trade and commerce. Hence there is a need for translation of data and texts from English into Indian languages and vice-versa.

(4) The practical utility and importance of translation has been growing in India for the following reasons: At the University level the medium of instruction is changed into regional languages in some faculties. As a number of source texts are available in English alone in many disciplines, translating these texts into regional languages is imperative not only for enriching and expanding the regional languages but also for meeting the requirements of higher education. Many of the Universities have either introduced, or are planning to introduce special courses in translation. The press and media are rapidly expanding in regional languages.

ii) The press and media are rapidly expanding in regional languages. The journalists who work under deadlines have to be aware of translation process, as they have to translate and-edit national and international news available largely in English, and make the information accessible to people with no loss of time.

iii) The multi-lingual urban societies need translation as a tool for more effective and meaningful communication. Otherwise there is a possibility of misunderstanding and mutual distrust among different sections of society.

iv) With a view to promoting cultural harmony the Sahitya Academy, New Delhi, is encouraging translations of regional literatures from one language to another and into English and vise-versa.

v) With the fast growth of information technology and Internet media, translation has become an immediately felt need.

vi) As the educational technology, which is available only in English, has been introduced in school education; and the source materials in educational technology which are available only in English, and they are to be translated into all the regional languages of India.

vii) In a democratic country like India legislative bodies like parliament and state assemblies do transact the affairs in the national language Hindi and also in other regional languages. In this context automatic data processing and machine translation have become the need of the hour. Hence, the methods of sophisticated machine translations have to be developed.

viii) There is a necessity to promote translation as a subject from secondary school level to postgraduate level, so as to enable the students to creatively interact while engaged in translation.

In view of the above-mentioned factors, a study of the practice and problems of translation acquires significance. It may not be out of place to quote here the views of Alien Tate who emphasized the inevitability of translation inspite of its problems and impossibilities. Tate observes: "Translation is forever impossible and for ever necessary." 1

\section{Method:}

In the twentieth century, a radical change occurred in translation theory arid practice as new concepts and communication had developed. A number of theoreticians, scholars, scientists and psychologists have suggested various principles of translations. Accordingly, different types and methods of translations have been explored. Some of them are briefly discussed below:

\section{Types Of Translation:}

Translation based on purpose:

These types of translations have the purpose or end of the translation as the translation as the basic need. For example Casagrande (1954) provided the following classification of translations directed towards purpose.

i. Pragmatic translation: It refers to the translation of a message with a focus on accuracy of the information meant to be conveyed in the SL form. Translators have no concern other than conveying information in the Second Language (e.g., translation of technical and legal documents)

ii. Aesthetic - poetic translation: In this translation, the translator takes into the account of the effects, emotion and feelings of the original language rendition, the aesthetic form (e.g. Sonnet, Heroic Couplet, Dramatic monologue) used by the original author as well as any information in the message (e.g., Translation of literary texts)

iii. Ethnographic Translation: Its purpose is to explicate the cultural context of the source and the target language versions. With this object, translators have to be sensitive to the way-words that are used 
(e.g., Yee versus yea in American English) and must know how the words fit into the cultures that use the SL and the TL.

iv. Linguistic Translation: It concerns with equivalent meanings of the constituent morphemes of the second language and with grammatical form (e.g., Machine translation). ${ }^{2}$

v. Phonemic translation: This attempts to produce the SL sound in the TL while at the same time producing an acceptable paraphrase of the sense. Lefevere comes to the conclusion that although this works moderately well in the translation of onomatopoeia, the overall result is clumsy and often devoid of sense altogether.

vi. Literal translation: In this the emphasis on word-for-word translation distorts the sense and the syntax of the original.

vii. Metrical translation: Here the criterion is adopted to reproduce the metre of the SL text. This is possible when the two languages have shared the metre.

viii. Poetry in Prose: In this type Lefevere concludes that distortion of the sense, communicative value and syntax of the SL text results from this method, although not to the same extent as with the literal or metrical types of translation.

ix. Rhymed translation: In this translation the translator 'enters into a double bondage' of meter and rhyme, Lefevere's conclusions here are particularly harsh, since he feels that the end product is merely a 'caricature' of Catullus.

x. Blank Verse translation: In this theory, restrictions imposed on the translator by the choice of structure are emphasized, although the greater accuracy and higher degree or literalness obtained are also noted.

xi. Interpretation: Under this heading of translation the version where the substance of SL text is retained but the form is changed, and imitations where the translator produces a poem of his own which has 'only title and point of departure, if those, in common with the source text.'

xii. This is an empirical study based upon the translation of select literary texts in English translated into Telugu. The texts (short stories in English) selected and their translations are given in the following table-I

TABLE - I

\begin{tabular}{|l|l|l|l|}
\hline \multicolumn{2}{|l|}{ Source Language - English } & \multicolumn{2}{l|}{ Target Language - Telugu } \\
\hline Author & Title & Translator & Title \\
\hline Bhabani Bhattacharya & A Moment of Eternity & N.Venugopal & Ananta Kshanam \\
\hline R.K.Narayan & Another Community & V. V.B.Rama Rao & Maroo Jaathi \\
\hline Mulk Raj Anand & The Golden Watch & Kakani Chakrapani & Bangaru Gadiyaaramu \\
\hline Anita Desai & The Accompanist & A.Subba Rao & Pakka Vaadyagaadu \\
\hline
\end{tabular}

In addition to the above, two English novels translated into Telugu are selected for this study. They are given in the following Table - II

TABLE - II

\begin{tabular}{|l|l|l|l|}
\hline Source Language - English & Target Language - Telugu \\
\hline Author & Title & Translator & Title \\
\hline R.L. Stevenson & Treasure Island & Nanduri Rama Mohana Rao & Kaanchana Dweepam \\
\hline Mark Twain & $\begin{array}{l}\text { Adventures of Huckleberry } \\
\text { Finn }\end{array}$ & Nanduri Rama Mohana Rao & Huckleberry Finn \\
\hline
\end{tabular}

\section{Result:}

(i) Translation is both linguistic and cultural activity and it concerned with communication of meaning. It is not merely a work finding lexical equivalents i.e., TL equivalents of SL words, but much more, as it involves cultural, aesthetic, ethical, social, scientific and metaphysical dimensions of SL and TL. The translator should possess equal insights into which the text of SL is translated from which the translation is to be made and the target language to which the translation is to be done.

If the translator does not have command over both the languages and the words do not "obey his call" and lacks a "feel" of the language, his translation may not be put up to the mark.

Language is largely a culture oriented and therefore translators face the problem of translating certain culture based words into another language with different culture. Colloquial expression, slang proverbs and some dialectical expressions are difficult to translate and the equivalence of words in two or more languages is hard to establish. 
(ii) It is easy to translate from one Indian language into another Indian language because the cultural ethos is more or less is common. But the translation from an Indian language into English is a hard task and problematic one. For instance, in Indian languages there are honorific terms of address indicative of the social distance between the speaker and addressee, but they do not have equivalents in English and so create problems in translation Meeakshi Mukherjeee makes an apt observation on this subject. According to her,"The act of translation is voluntary, that is the material has been chosen by the translator himself and the prime mover is a compelling desire to recreate.

\section{Conclusion}

"The translator is a writer in the language in which he is translating that is not merely competent but creative" Stressing upon the main complication and problems that arise in translation as G.N. Devy mentions:

Owing to its bilingual involvement, translation poses highly complicated problems before the literary theorists. The most complicated and defeating problem is, what makes a good translation "good?" While it is also difficult to sort out such an issue in relation to poetry or fiction, there are atleast some attempts to pressure that aesthetics of literature can be related to some criteria as "organic structure", "relevant form", "complexity", or "imagination".

The translation problem is more of an aesthetic problem than a purely linguistic problem. Literary translation is not just a replication of text in another verbal system of signs. It is a replication of an ordered subsystem of signs with in a language to another correspondingly ordered sub-system of signs with in a related language?

\section{References}

[1]. Bijay Kumar Das. The Horizon of Translation, (New Delhi: Atlantic Publishers, 1998) p.1

[2]. J.C. Catford, A Linguistic Theory of Translation, (London: Oxford University Press, 1965) p.20.

[3]. S.K. Verma in, Translation From Periphery to Centre stage, (New Delhi: Prestige Books, 1998) p.15.

[4]. K.M. George in, Translation From Periphery to Cent restage, (New Delhi: Prestige Books, 1998) p.32.

[5]. Manorama Year Book, 2003: pp.524 - 527.

[6]. S.S. Prabhakar Rao in, Translation From Periphery to Centresta.ge, (New Delhi: Prestige Books, 1998$)$ p. 171.

[7]. Bijay Kumar Das, The Horizon of Translation, (New Delhi: Atlantic Publishers, 1998) p.24

[8]. Theodore Savory, The Art of Translation, (London: Jonathan Cape, 1959) pp.57-59.

[9]. Eugene A. Nida, A Framework for the Analysis and Evolution of Theories of Translation. (Leiden: Drill, 1974) pp.59-60.

[10]. Quoted by S.D. Tirurnala Rao: Translation from Periphery to Centrestage. (New Delhi: Prestige Books, 1998) p.75.

[11]. Casagrande, The Ends of Translation, (International Journal of American Linguistics), (1954: 20) pp.335-340.

[12]. Theodore Savory, The Art of Translation of London: Jonathan cape, 1959) pp.18-23.

[13]. Quoted by Van Dijk. I9S3. pp. 34-36 in The Incorporate Linguist Vol. 18 No.I. 1979, pp. 10-15.

[14]. Roman Jacabson, On Linguistic Aspects of Translation. (New York: Oxford University Press, 1966) p. 233.

[15]. Susan Bassnett, Translation Studies, (London, Methuen, 1980) pp. 81-82.

[16]. House, Juliane, A Model for Translation Quality Assessment (Tubingen Guntger Narr. 1977) p. 15.

[17]. Bijay Kumar Das, The Horizon of Translation,(New Delhi: Atlantic Publishers, 1998) p.39.

[18]. P.V. Dhamija, CIEFL Bulletin, New Series Vol. IV, June-Dec. 1992, I, pp. 1-2.

[19]. Susan Bassnett - McGuire, Translation Studies, (London, Methuen, 1980) p. 109.

[20]. B.K. Das, The Horizon of Translation. (New Delhi: Atlantic Publishers, 1998) pp.33-34.

[21]. Meenakshi Mukherjee, Transposition of culture, Cygnus 2: 2 (1981): p 73-74.

[22]. G.N. Devy, Translation From Periphery to Centre Stage, (New Delhi: Prestige Books, 1998), pp.52-56.

[23]. Amitav Ghosh, Indian Express, (1994: March), p.20. 